\title{
Removal Methods of Heavy Metals from Laboratory Wastewater
}

\author{
Tamirat Dula Chaemiso* Tariku Nefo \\ Department of Chemistry, College of Natural and Computational Sciences, Wolaita Sodo University, P.O. Box \\ 138, Wolaita Sodo, Ethiopia
}

\begin{abstract}
The removal of heavy metals from the environment is the special concern due to their persistence without degradation. Methods for treating laboratory and industrial wastewater containing heavy metals often involve technologies for reduction of toxicity in order to meet technology-based treatment standards. Physico-chemical removal processes such as; adsorption on new adsorbents, ion exchange, membrane filtration, electrodialysis, reverse osmosis, and ultrafiltration were discussed. Their advantages and drawbacks in application were evaluated. In the processes of biological treatments microorganisms play a role of settling solids in the solution. Activated sludge, trickling filters, stabilization ponds are widely used for treating industrial wastewater. Bioadsorption is a new biological method and various low cost bioadsorbents (agricultural waste, forest waste, industrial waste, algae etc.) are used for maximum removal of heavy metals from wastewater. Bioadsorption techniques are eco friendly best solutions for removing heavy metals from wastewater rather than physicchemical methods. But chemical methods are most suitable treatments for toxic inorganic compounds produced from various industries which cannot removed from any biological and physical techniques.
\end{abstract}

Keywords: Heavy metals; removal techniques; Bioadsorption; physico-chemical treatments DOI: $10.7176 / J N S R / 9-2-04$

\section{Introduction}

Heavy metals are the chemical elements having relative density greater than 5 . The chronic exposure of toxic dose of these metals in humans results in various complications in nervous system, respiratory system, renal system, hepatic system as well as reproductive system. Metals are also reported to cause allergies and repeated long-term contact with some metals or their compounds may even prove carcinogenic. Most of the heavy metals are well known toxic and carcinogenic agents and represents a serious threat to the human population and the fauna and flora of the receiving water bodies as they are persistent and non-biodegradable. Heavy metals present in the wastewaters discharged from laboratories and industries are a subject of major concern for the environmental issues. When these metal ions present at excessive levels in an aqueous discharge, the stream remains unusable due to the adverse effects associated with consumption [1].These metal ions are highly toxic and if they are directly discharged can cause environmental imbalance and can damage the subsequent treatments associated in the wastewater purification plants. Therefore, inexpensive and efficient methods of wastewater purification or improvements in the existing methods will have to be made to adjust the new requirements [3]. Therefore efficient and effective methods are needed especially for chemical and industrial laboratories. Heavy metals present in wastewater of laboratory effluent are major concern of environmental pollution. Heavy metals are generally considered those whose density exceeds $5 \mathrm{~g}$ per cubic centimeter. Most of the elements falls into this category are highly water soluble, well-known toxics and carcinogenic agents.

Heavy metals are considered to be the following elements: Copper, Silver, Zinc, Cadmium, Gold, Mercury, Lead, Chromium, Iron, Nickel, Tin, Arsenic, Selenium, Molybdenum, Cobalt, Manganese, and Aluminum. They represent serious threats to the human population and the fauna and flora of the receiving water bodies [2]. They can be absorbed and accumulated in human body and caused serious health effects like cancer, organ damage, nervous system damage, and in extreme cases, death. Also it reduces growth and development. Whenever toxic heavy metals are exposed to the natural eco-system, accumulation of metal ions in human bodies will occur through either direct intake or food chains. Therefore, heavy metals should be prevented from reaching the natural environm3ent [3]. In order to remove toxic heavy metals from water systems, conventional methods have been used such as chemical precipitation, coagulation, ion exchange, electrochemical treatments, filtration, electro dialysis, membrane methods and biological methods [4].

Adsorption of heavy metals on conventional adsorbents such as activated carbon have been used widely in many applications as an effective adsorbent, and the activated carbon produced by carbonizing organic materials is the most widely used adsorbent. However, the high cost of the activation process limits its use in wastewater treatment applications [5]. Therefore, among these methods precipitation is most economical and widely used in many laboratories.

Agricultural waste is one of the rich sources of low-cost adsorbents besides industrial by-product and natural material. Due to its abundant availability agricultural waste such as peanut husk, rice husk, wheat bran and sawdust offer little economic value and, moreover, create serious disposal problems [6]. Activated carbons derived from peanut husk and rice husk have been successfully employed for the removal of heavy metals from 
aqueous solutions [7]. The use of peanut husk carbon for the adsorption of $\mathrm{Cu}$ (II) from wastewater was studied by Periasamy and Namasivayam [8].

Thus, Natural materials locally available in certain regions can be employed as low-cost adsorbents due to their metal binding capacity. Zeolites are naturally occurring hydrated alumina silicate minerals. The structures of zeolites consist of three-dimensional frameworks of $\mathrm{SiO}_{4}^{+}$and $\mathrm{AlO}_{4}^{+}$tetrahedral. The fact that solute exchangeable ions are relatively innocuous (sodium, calcium and potassium ions) makes them particularly suitable for removing undesirable heavy metal ions from laboratory effluent waters. The adsorption behavior of natural zeolites (Clinoptilolite) with respect to $\mathrm{Co}^{2+}, \mathrm{Cu}^{2+}, \mathrm{Zn}^{2+}$ and $\mathrm{Mn}^{2+}$ was studied by Erdemetal and the results show that natural zeolites can be used effectively for the removal of metal cations from wastewater [10].

\section{OBJECTIVE OF THE STUDY}

\subsection{General Objective}

To assess the removal methods of heavy metals from laboratory waste water

\subsection{Specific Objectives}

To reduce environmental pollution caused by heavy metals present in laboratory waste water.

To enhance the concept of people removing the laboratory waste water on the health impacts depending on the level of heavy metals present in it.

\section{Materials and Methods}

\subsection{Experimental Site}

The study was conducted in reviewing and searching different literatures which provide more information about removal of heavy metals from effluence of wastewater which discharge from chemical laboratories and industries at Wolaita Sodo University, Ethiopia.

\subsection{Study design}

The study design of this literature review was included different campus of factories, industries and higher institution that discharges wastewater that contaminated with heavy metals.

\subsection{Sampling tools}

The type of water sampling tool required has been depending up on the sampling site and the type of sample to be taken. Sampling can be achieved using buckets, open water grab samplers, reagent bottles and other messenger activated samplers.

The type of material such tools made of was depend up on the purpose (target analyses) of the study, but relatively inert materials such as stainless steel, synthetic resin such as polypropylene, polyethylene or pertetrafluoroethylene (PTFE), or glass are all acceptable.

\subsection{Sample containers}

The size and type of sample to be taken was based up on the sample container and the amount have been enough for determine the required concentration of heavy metals. The type of sample container required should not make reaction with sample constituents. For inorganic compounds such as heavy metals, use polyethylene or glass containers.

\subsection{Cleanliness}

Sampling tools and containers have been contamination free. The method and extent of cleaning was used to determine relatively the exact concentration of target analyses and to enhance instrumental detection limits. However, possible use tools and sample containers which have been cleaned thoroughly. In particular, for heavy metals used containers were washed with $10 \% \mathrm{v} / \mathrm{v}$ nitric acid, or $16 \% \mathrm{v} / \mathrm{v}$ hydrochloric acid, and then rinsed several times with pure (deionizer) water.

\subsection{Sampling operation}

The number and volume (size) of the samples to be collected was depend up on the number and concentration of the target analytes, the difficulty and expense of analysis, and whether extra storage is required. The water sample Collected from different chemical laboratories using the most appropriate sampling tools based up on the nature of the sampling site, the target analytes, and the instrument on which quantitative measurement was to be performed. Sample containers were washed from 3-4 times with water from the exact site of sampling prior to taking the sample. The samples were carefully and gently poured into its container without making bubbles.

For inorganic compounds such as heavy metals, the container has been approximately $80-90 \%$ filled with the water sample (the space above the surface of the water sample allows thorough mixing just prior to analysis). 


\section{Result and Discussion}

Heavy metal removal may be accomplished by different mechanism.

\subsection{Physico-chemical methods}

Adsorption is a physicochemical treatment processes which help in effective removal of heavy metals from metal contaminated wastewater and is one of the most preferred and efficient method. Its major advantage includes effectiveness at both high/low contaminant concentrations, selectivity by employing tailored adsorbents, regeneration ability of used adsorbents and a comparatively low cost.

Basically, adsorption is a mass transfer process and substances bound by physical and/or chemical interactions to solid surface [3]. Various low-cost adsorbents, derived from agricultural waste, industrial byproduct, natural material, or modified biopolymers, have been recently developed and applied for the removal of heavy metals from metal-contaminated water.

Recently, research for the removal of heavy metals from industrial effluent has been focused on the use of agricultural by-products as adsorbents through biosorption process. New resources such as hazelnut shell, rice husk, pecan shells, jackfruit, maize cob or husk, rice straw, rice husk, coconut shell etc can be used as an adsorbent for heavy metal uptake after chemical modification [3, 17]. They found that the maximum metal removal occurred by those biomass due to containing of cellulose, lignin, carbohydrate and silica in their adsorbent [15].

Biopolymers are posse a number of different functional groups, such as hydroxyls and amines, which increase the efficiency of metal ion uptake [13]. They are widely use in industrially as they are capable of lowering transition metal ion concentrations to sub-part per billion concentrations. New polysaccharide-basedmaterials are described as biopolymer adsorbents (derived from chitin, chitosan, and starch) for the removal of heavy metals from the wastewater. The sorption mechanisms of polysaccharide-based-materials are complicated and depend on the value of $\mathrm{pH}[16]$.

The various adsorbents and corresponding heavy metals

\begin{tabular}{|c|c|c|c|}
\hline Adsorbent & Modifying agent(s) & Heavy Metal & $Q_{\max }\left(\mathrm{mg} \mathrm{g}^{-1}\right)$ \\
\hline Rice husk & $\begin{array}{lr}\text { Sodium } & \text { hydroxide } \\
\text { Sodium } & \text { bicarbonate } \\
\text { Epichlorohydrin } & \\
\end{array}$ & $\mathrm{Cd}(\mathrm{II})$ & $\begin{array}{l}8.58 \\
20.24 \\
16.18 \\
11.12\end{array}$ \\
\hline $\begin{array}{l}\text { Sawdust }(\text { C.deodarwood) } \\
\text { Sawdust (S. Robust a) } \\
\text { Sawdust (Poplar tree) } \\
\text { Sawdust } \\
\text { (Dalbergiasissoo) } \\
\text { Sawdust(Poplar tree) } \\
\text { Sawdust (Pinussylvestris) }\end{array}$ & $\begin{array}{lr}\text { Sodium } & \text { Hydroxide } \\
\text { Formaldehyde } & \\
\text { Sulfuric } & \text { acid } \\
\text { Formaldehyde in Sulfuric acid } & \end{array}$ & $\begin{array}{l}\mathrm{Cd}(\mathrm{II}) \\
\mathrm{Cr}(\mathrm{VI}) \\
\mathrm{Cu}(\mathrm{II}) \\
\mathrm{Ni}(\mathrm{II}) \\
\mathrm{Cu}(\mathrm{II}) \\
\mathrm{Zn}(\mathrm{II}) \\
\mathrm{Pb}(\mathrm{II}), \\
\mathrm{Cd}(\mathrm{II})\end{array}$ & $\begin{array}{l}73.62 \\
3.6 \\
13.95 \\
10.47 \\
6.92 \\
15.8 \\
9.78 \\
9.29\end{array}$ \\
\hline Groundnut husk & Sulfuric acid followed by silver impregnation & $\mathrm{Cr}(\mathrm{VI})$ & 11.4 \\
\hline Wheat bran & Sulfuric & $\begin{array}{l}\mathrm{Cu}(\mathrm{II}) \\
\mathrm{Cd} \text { (II) }\end{array}$ & $\begin{array}{l}51.5 \\
101\end{array}$ \\
\hline Banana pith & Nitric acid & $\mathrm{Cu}(\mathrm{II})$ & 13.46 \\
\hline Cork powder & $\begin{array}{l}\text { Calcium Chloride, } \\
\text { Sodium Hydroxide }\end{array}$ & $\mathrm{Cu}(\mathrm{II})$ & $\begin{array}{l}15.6 \\
19.5 \\
18.8\end{array}$ \\
\hline Corncob & $\begin{array}{l}\text { Nitric } \\
\text { Citric acid }\end{array}$ & $\mathrm{Cd}(\mathrm{II})$ & $\begin{array}{l}19.3 \\
55.2\end{array}$ \\
\hline Sugarcane biogases & Sodium bicarbonate & $\begin{array}{l}\mathrm{Cu}(\mathrm{II}) \\
\mathrm{Pb}(\mathrm{II}) \\
\mathrm{Cd}(\mathrm{II})\end{array}$ & $\begin{array}{l}114 \\
196 \\
189\end{array}$ \\
\hline Sugar beet pulp & Hydrochloric acid & $\begin{array}{l}\mathrm{Cu}(\mathrm{II}) \\
\mathrm{Zn} \text { (II) }\end{array}$ & $\begin{array}{l}0.15 \\
0.18\end{array}$ \\
\hline Coir pith & $\mathrm{ZnCl}_{2}$ & $\begin{array}{l}\mathrm{Cr}(\mathrm{VI}) \\
\mathrm{Ni}(\mathrm{II}) \\
\mathrm{Hg}(\mathrm{II}) \\
\mathrm{Cd}(\mathrm{II})\end{array}$ & NA \\
\hline
\end{tabular}

Table 1: The various modified plant wastes as adsorbents for the removal of heavy metal ions from aqueous solution containing metals [17]. 
Majority of these adsorbents are chemically modified plant waste substances. The aqueous solution mentioned includes waste water from different chemical industries and other synthetically made metal solutions for the purpose of study. Chemical pre-treatment of adsorbent results in higher adsorption capacity with respect to unmodified form. This is because pre-treatment causes higher number of active binding sites, better ion exchange properties and formation of new functional groups which have higher capacity of metal uptake. Chemical pre-treatment can be done by numerous chemicals which include mineral and organic acids, bases, oxidizing agent, organic compounds, etc.

The other conventional chemical processes for removing heavy metals from wastewater include many processes such as chemical precipitation, flotation, Coagulation - Flocculation, ion exchange, Membrane Filtration, Biological Methods and electrochemical deposition.

\subsection{Chemical Precipitation}

Chemical precipitation is one of the most widely used methods for heavy metal removal from inorganic effluent in laboratory and even in industry due to its simple operation [12]. These conventional chemical precipitation processes produce insoluble precipitates of heavy metals as hydroxide, sulfide, carbonate and phosphate. The mechanism of this process is based on to produce insoluble metal precipitation by reacting dissolved heavy metals in the waste water solution which discharge from chemical laboratory.

In the precipitation process very fine particles are generated and chemical precipitants, coagulants, and flocculation processes are used to increase their particle size to remove them as sludge $[11,13]$. Once the metals precipitate and form solids, they can easily be removed, and low metal concentrations can be discharged. Removal percentage of metal ions in the solution may be improved to optimum by changing major parameters such as $\mathrm{pH}$, temperature, initial concentration, charge of the ions etc. The most commonly used precipitation technique is hydroxide treatment due to its relative simplicity, low cost of precipitant (lime), and ease of automatic $\mathrm{pH}$ control. The solubility of the various metal hydroxides is minimized for $\mathrm{pH}$ in the range of 8.0 to $11.0[8]$

\subsection{Coagulation - Flocculation}

The coagulation-flocculation mechanism is based on the potential of the electrostatic interaction between pollutants and coagulant-flocculants agents [7]. The commonly used metal coagulants fall into two general categories: those based on aluminum and those based on iron. The aluminum coagulants include aluminum sulfate, aluminum chloride and sodium aluminates. The iron coagulants include ferric sulfate, ferrous sulfate, ferric chloride and ferric chloride sulfate. Other chemicals used as coagulants include hydrated lime and magnesium carbonate. The effectiveness of aluminum and iron coagulants arises principally from their ability to form multi-charged poly nuclear complexes with enhanced adsorption characteristics. The nature of the complexes formed may be controlled by the $\mathrm{pH}$ of the system. When metal coagulants are added to water the metal ions ( $\mathrm{Al}$ and $\mathrm{Fe}$ ) hydrolyze rapidly.

Flocculation process continually increases the particle size to discrete particles through additional collisions and interaction with inorganic polymers formed by the organic polymers added [15]. Once discrete particles are flocculated into larger particles, they can be removed or separated by filtration, straining or floatation. Production of sludge, application of chemicals and transfer of toxic compounds into solid phase are main drawbacks of this process.

\subsection{Electrochemical Treatments}

Electrolysis: Electrolytic recovery is one of the technologies used to remove metals from wastewater streams. This process uses electricity to pass a current through an aqueous metal-bearing solution containing a cathode plate and an insoluble anode. Electricity can be generated by movements of electrons from one element to another.

Electrochemical process to treat wastewater containing heavy metals is to precipitate the heavy metals in a weak acidic or neutralized catholyte as hydroxides. Electrochemical treatments of wastewater involve electrodeposition, electro-coagulation, electro-flotation and electro-oxidation [16].

Electrode stabilization of colloids is called coagulation and precipitation by hydroxide formation to acceptable levels. It is the most common heavy metal precipitation method forming coagulants by electrolytic oxidation and destabilizing contaminants to form flocculants [17]. In the electro-coagulation process the coagulant is generated in site by electrolytic oxidation of an appropriate anode material. In this process, charged ionic metal species are removed from wastewater by allowing it to react with anion in the effluent. This process is characterized by reduced sludge production, no requirement for chemical use, and ease of operation.

\subsection{Ion Exchange}

Ion exchange is a reversible chemical reaction wherein an ion (an atom or molecule that has lost or gained an 
electron and thus acquired an electrical charge) from a wastewater solution is exchanged for a similarly charged ion attached to an immobile solid particle. These solid ion exchange particles are either naturally occurring inorganic zeolites or synthetically produced organic resins.

Ion exchange can attract soluble ions from the liquid phase to the solid phase, which is the most widely used method in water treatment industry. In ion exchange process cations or anions containing special ion exchange is used to remove metal ions in the solution. Commonly used ion exchangers are synthetic organic ion exchange resins.

Ion exchange resins are water-insoluble solid substances which can absorb positively or negatively charged ions from an electrolyte solution and release other ions with the same charges into the solution in an equivalent amount. The positively charged ions in cationic resins such as hydrogen and sodium ions are exchanged with positively charged ions, such as nickel, copper, zinc, Copper, Silver, Cadmium, Gold, Mercury, Lead, Chromium, Iron, Tin, Arsenic, Selenium, Molybdenum, Cobalt, Manganese, and Aluminum ions in the solutions. Similarly, the negative ions in the resins such as hydroxyl and chloride ions can be replaced by the negatively charged ions such as chromate, sulfate, nitrate, cyanide and dissolved organic carbon (DOC).

In a water deionization process, the resins exchange hydrogen ions $\left(\mathrm{H}^{+}\right)$for the positively charged ions (such as nickel, copper, and sodium) and hydroxyl ions $\left(\mathrm{OH}^{-}\right)$for negatively charged sulfates, chromates and chlorides. Because the quantity of $\mathrm{H}^{+}$and $\mathrm{OH}^{-}$ions is balanced, the result of the ion exchange treatment is relatively pure, neutral water. Ion exchange reactions are stoichiometric and reversible, and in that way they are similar to other solution phase reactions. For example:

$$
\mathrm{NiSO}_{4}+\mathrm{Ca}(\mathrm{OH})_{2} \rightarrow \mathrm{Ni}(\mathrm{OH})_{2}+\mathrm{CaSO}_{4}
$$

In this reaction, the nickel ions of the nickel sulfate $\left(\mathrm{NiSO}_{4}\right)$ are exchanged for the calcium ions of the calcium hydroxide $\mathrm{Ca}(\mathrm{OH})_{2}$ molecule. Similarly, a resin with hydrogen ions available for exchange will exchange those ions for nickel ions from the wastewater solution

\subsection{Membrane Filtration}

Membrane filtration has received considerable attention for the treatment of inorganic effluent. It is capable of removing heavy metals, suspended solid, inorganic contaminants and organic compounds. Depending on the size of the particle that can be retained, various types of membrane filtration such as ultra-filtration, nano-filtration and reverse osmosis can be employed for heavy metal removal from wastewater.

Ultra filtration (UF) utilizes permeable (selective) membrane to separate heavy metals, macromolecules and suspended solids from inorganic solution on the basis of the pore size $(5-20 \mathrm{~nm})$ and molecular weight of the separating compounds [11]. Depending on the membrane characteristics, UF can achieve more than $90 \%$ of removal efficiency with a metal concentration ranging from 10 to $112 \mathrm{mg} / \mathrm{L}$ at $\mathrm{pH}$ ranging from 5 to 9.5 and at 2-5 bar of pressure. UF presents some advantages such as lower driving force and a smaller space requirement due to its high packing density.

Polymer-supported ultrafiltration (PSU) technique adds water soluble polymeric ligand to bind metal ions and form macromolecular complexes by producing a free targeted metal ions effluent [12]. Advantages of the PSU technology are the low-energy requirements involved in ultra filtration, the very fast reaction kinetics and higher selectivity of separation of selective bonding agents in aqueous solution.

Another similar technique, complexation-ultrafiltration (CU), proves to be a promising alternative to technologies based on precipitation and ion exchange. The use of water-soluble metal-binding polymers in combination with ultra filtration (UF) is a hybrid approach to concentrate selectively and to recover heavy metals in the solution. In the complexation - UF process cationic forms of heavy metals are first complexes by a macroligand in order to increase their molecular weight with a size larger than the pores of the selected membrane [13, 16]. The advantages of complexation-filtration process are the high separation selectivity due to the use of a selective binding and low-energy requirements involved in these processes. Water-soluble polymeric ligand has shown to be powerful substances to remove trace metals from aqueous solutions and industrial wastewater through membrane processes.

Reverse osmosis (RO) is a separation process that uses pressure to force a solution through a membrane that retains the solute on one side and allows the pure solvent to pass to the other side. The membrane here is semipermeable, meaning it allows the passage of solvent but not for metals. The membranes used for reverse osmosis have a dense barrier layer in the polymer matrix where most separation occurs. Reverse osmosis can remove many types of molecules and ions from solutions including bacteria. Reverse osmosis involves a diffusive mechanism, so that separation efficiency is dependent on solute concentration, pressure, and water flux rate [15].

\subsection{Electro dialysis}

Electro dialysis (ED) is a membrane separation in which ionized species in the solution are passed through an ion exchange membrane by applying an electric potential. The membranes are thin sheets of plastic materials 
with either anionic or cationic characteristics. When a solution containing ionic species passes through the cell compartments, the anions migrate toward the anode and the cations toward the cathode, crossing the anion exchange and cation-exchange membranes [9]. A noticeable disadvantage is membranes replacement and the corrosion process [8]. Using membranes with higher ion exchange capacity resulted in better cell performance. Effects of flow rate, temperature and voltage at different concentrations using two types of commercial membranes, using a laboratory ED cell, on lead removal were studied [7]. Results show that increasing voltage and temperature improved cell performance and separation percentage decreased with an increasing flow rate. This offers advantages for the treatment of highly concentrated wastewater laden with heavy metals to recovery undesirable impurities from water.

\subsection{Biological Methods}

Biological removal of heavy metals in wastewater involves the use of biological techniques for the elimination of pollutants from wastewater. In this processes microorganisms play a role of settling solids in the solution. Activated sludge, trickling filters, stabilization ponds are widely used for treating wastewater.

Activated sludge is the most common option uses microorganisms in the treatment process to break down organic material with aeration and agitation, and then allows solids to settle out. Bacteria-containing "activated sludge" is continually re-circulated back to the aeration basin to increase the rate of organic decomposition. Most of the research on heavy metals removal in biological systems has been directed towards the suspended growth activated sludge process.

Trickling filters which consist of beds of coarse media (often stones or plastic) deep help to grow microorganisms. Wastewater is sprayed into the air (aeration), and then allowed to trickle through the media and microorganisms break down organic materials in the wastewater. Trickling filters drain at the bottom and the wastewater is collected and then undergoes sedimentation. Stabilization ponds or lagoons are slow, cheap, and relatively inefficient, biological method that can be used for various types of wastewater. They rely on the interaction of sunlight algae; microorganisms and oxygen make the heavy metal constituents to undertake biodegradation process.

\subsection{Evaluation of heavy metal removal processes}

Removal of heavy metals from the effluent is very important part of the research carried out in environmental field. Various methods tried by the researchers include physical, chemical and biological methods.

Physico-chemical treatments offer various advantages such as rapid process, easy operation and control various input loads etc. Whenever it is required, chemical plants can be modified. These treatment systems require a lower space and installation cost. Their benefits are outweighed by a number of drawbacks such as their high operational costs due to the chemicals used, high-energy consumption and handling costs for toxic sludge disposal. If the chemical costs are possible to reduce anyhow, physico-chemical treatments have been found as one of the most suitable treatments for inorganic compounds produced from various industries which cannot removed from any biological and physical techniques.

Chemical precipitation requires a large amount of chemicals to reduce metals to an acceptable level for discharge. Other drawbacks are huge sludge production, slow metal precipitation, poor settling, the aggregation of metal precipitates, and the long-term environmental impacts of sludge disposal [11]. It changes the aqueous pollution problem to a solid waste disposal problem without recovering the metal.

Studies on biological methods are very important area of research with huge potential for research and applicability for removal of heavy metals. Various biological methods include trickling filter, biosorption; activated sludge process can be used. Biological methods by using various low materials were found be very effective methods with higher percentage of removal. Although biological methods are low cost and environmental friendly techniques they need large areas and proper maintenance and operation.

\section{Conclusions and Recommendation}

The problem of heavy metal pollution is worsening day to day due to human activities. Therefore, the removal of heavy metals from the effluent which discharge to the environment has been very importance. Removal of heavy metals can be done by both physical as well as chemical means.

For physical removal, adsorption and bio-sorption are employed mechanism while chemical removal mainly employs chelating. Adsorption of metal ions using plant waste products presents an effective as well as economical approach for heavy metal removal from aqueous effluent.

The stability and adsorption capacity of adsorbent can be enhanced by suitable pretreatment with alkali or acids which causes an increase in active binding sites, better ion exchange properties or may even lead to formation of new functional group that may favor metal ion uptake.

Biosorption is an effective technique used for heavy metal removal from aqueous wastes. For algae biomass, ion exchange is shown to play an important role in metal sequestering mechanisms. For yeast and bacteria, 
biosorption can be attributed to different cell wall constituents. This technique has been extensively used for treating heavy metal contamination especially in the waste water coming from electroplating, mining, industries and chemical laboratories which can contaminate the environment. It is also eco friendly best solutions for removing heavy metals from wastewater rather than physic-chemical methods. But chemical methods are most suitable treatments for toxic inorganic compounds produced from various industries which cannot removed from any biological and physical techniques.

\section{References}

[1] Hala Ahmed Hegazi, Removal of heavy metals from wastewater using agricultural and industrial wastes as adsorbents. HBRC Journal (2013) 9, 276-282

[2] Mona Karniba, Ahmad Kabbanib, Hanafy Holaila, Zakia Olamaa*, Heavy Metals Removal Using Activated Carbon, Silica and Silica Activated Carbon Composite. Energy Procedia 50 (2014) 113 - 120

[3] Omar E. Abdel Salam a, Neama A. Reiad b,*, Maha M. ElShafei b: A study of the removal characteristics of heavy metals from wastewater by low-cost adsorbents. Journal of Advanced Research (2011) 2, 297-303

[4] Javid Ali and 3Sudhair Abbas, Evaluation of Drinking Water for Heavy Metals of District Karak, Khyber Pakhtunkhwa.World Applied Sciences Journal 30 (4): 402-405, 2014

[5] Aleksandra StanojkovIc-sebIca, Radmila PIvIca, Dragana JosIca, Zoran DInIca, Aleksandar Stanojkovicb, Heavy Metals Content in Selected Medicinal Plants Commonly Used as Components for Herbal Formulations. JOURNAL OF AGRICULTURAL SCIENCES 21 (2015) 317-325

[6] Gian Carlo Cruz, Zaheer Din, Christian Dale Feri, Angela Mae Balaoing, Eva Marie Gonzales, Hannah Mia Navidad, Ma. Margot Flor Schlaaff, Jennifer Winter, ANALYSIS OF TOXIC HEAVY METALS (ARSENIC,LEAD, AND MERCURY) IN SELECTED INFANT FORMULA MILK COMMERCIALLY AVAILABLE IN THE PHILIPPINES BY AAS.ISSN: 2094-1749 Vol: 1 Issue: 1, 2009

[7] Oladunni Bola Olafisoye1*, Tejumade Adefioye, Otolorin Adelaja Osibote: Heavy Metals Contamination of Water, Soil, and Plants around an Electronic Waste Dumpsite. Pol. J. Environ. Stud. Vol. 22, No. 5 (2013), 1431-1439

[8] Gunatilake S.K., Methods of Removing Heavy Metals from Industrial Wastewater. Journal of Multidisciplinary Engineering Science Studies (JMESS) Vol. 1 Issue 1, November - 2015, ISSN: $2912-$ 1309.

[9] Alka A. Mungray*, Shrirang V. Kulkarni, Arvind K. Mungray**, Removal of heavy metals from wastewater using micellar enhanced ultrafiltration technique: a review. Cent. Eur. J. Chem. 10(1) • 2012 • 27-46.

[10] Priti Malhotra, Arti Jain, Removal of Heavy Metals from Laboratory Wastewater Using Waste Precursors: A Sustainable Approach. International Journal of Chemical, Environmental \& Biological Sciences (IJCEBS) Volume 5, Issue 1 (2017) ISSN 2320-4087.

[11] M.A.Barakat, New trends in removing heavy metals from industrial wastewater. Volume 4, Issue 4, October 2011, pages 361-377

[12] Jie-Chung Lou, Chien-Kuei Chang, Completely treating heavy metal laboratory waste liquid by an improved ferrite process. Separation and Purification Technology 57 (2007) 513-518

[13] Toxicity of heavy metals in the water of Ganga River at Varanasi, India: Environmental implication Singh et al., 2005; Marschner, 1995

[14] M. Öztürk, 2G. Özözen, 2O. Minareci, 2E. Minareci, DETERMINATION OF HEAVY METALS IN FISH, WATER AND SEDIMENTS OF AVSAR DAM LAKE IN TURKEY Iran. J. Environ. Health. Sci. Eng., argong et al; 2009, Vol. 6, No. 2, pp. 73-80

[15] Determination of Heavy Metal Levels in Fishes from the Lower Reach of the Kelantan River, Kelantan, Malaysia. Amman et al; 2002, Dec; 25(2): 21-39

[16] Heavy metal contamination and its indexing approach for river water. Int. J. Environ. Sci. Tech., 7 (4), 785 792, autumn 2010

[17] Amin O. Igwegbe, Chibugo H. Agukwe and Charles A. Negbenebor; A Survey of Heavy Metal (Lead, Cadmium and Copper) Contents of Selected Fruit and Vegetable Crops from Borno State of Nigeria. ISBN: 2319-6483, ISSN: 2278-4721, Vol. 2, Issue 1 